Supporting Information for jm-2015-015343

Enhanced Sphingomyelinase Activity Contributes to the Apoptotic Capacity of Electronegative Low-Density Lipoprotein

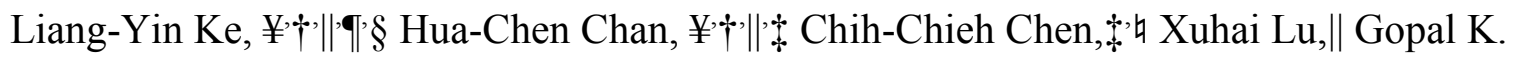

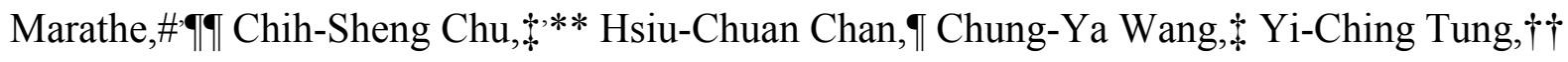

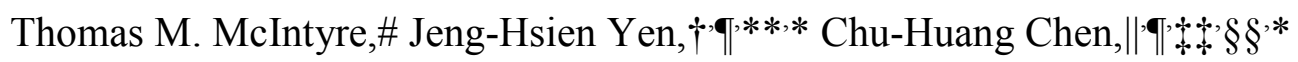

\title{
Supplemental Figure Legend
}

Supplemental Figure 1. Full mass scan for the comparison of lipid components in L1 versus L5.

Ceramide (18:0/16:0), ceramide (18:1/24:1), and ceramide (18:0/24:0) were 64-80\% higher in L5 than in $\mathrm{L} 1(\mathrm{n}=4 ; \mathrm{P}<0.05)$. Ceramide $(18: 1 / 25: 0)$ was about $98 \%$ higher in $\mathrm{L} 5$ than in $\mathrm{L} 1(\mathrm{n}=10$; $\mathrm{P}<0.05$ ). Note that some lipid targets were under the detection limit of full mass scan in certain samples. 


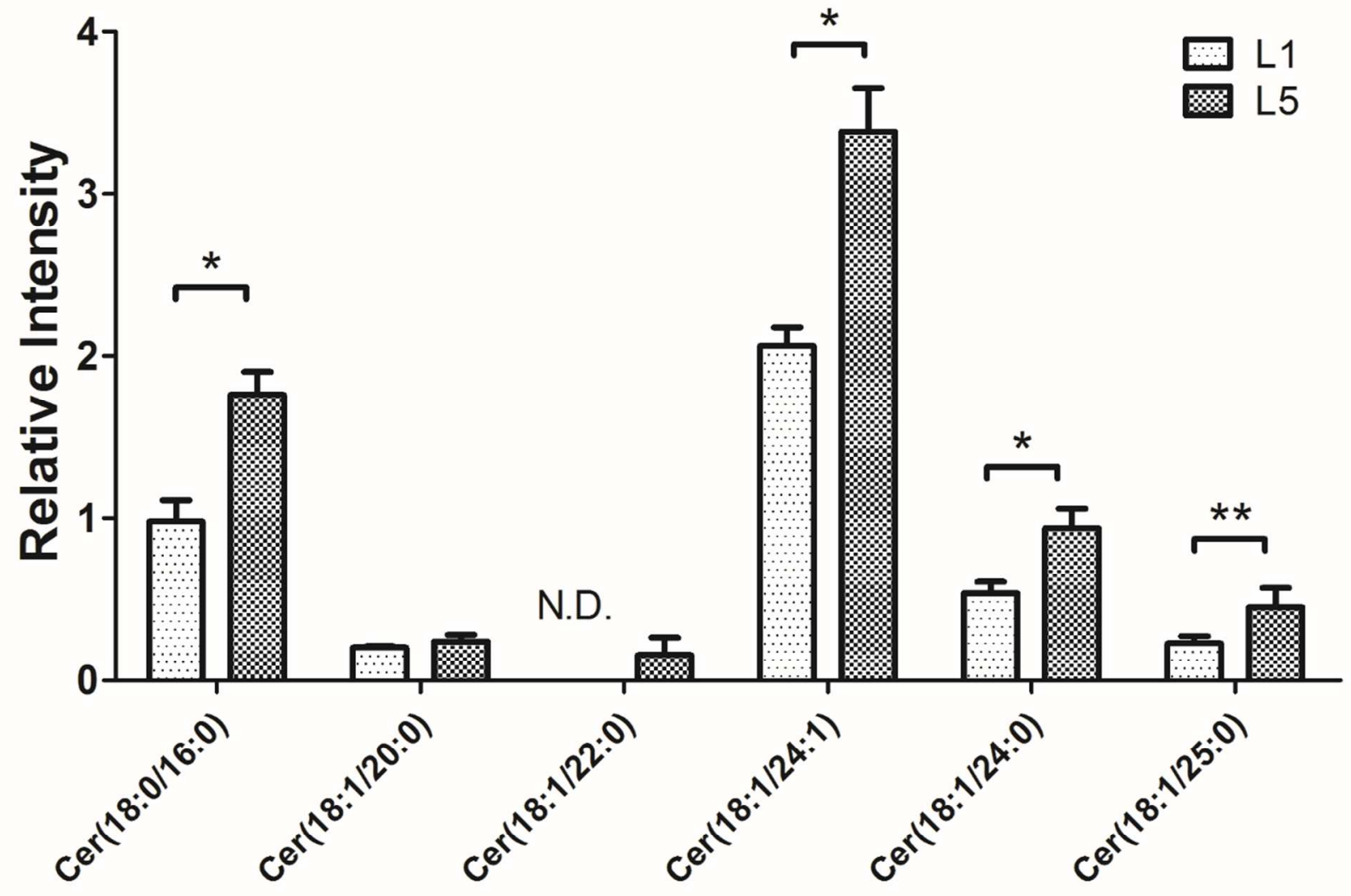

